\title{
Suitability of Gypsum and Crushed Waste Brick Mix for Stabilization of Weak Subgrade Soil
}

\author{
Assefa Takele Getaneh ${ }^{1}$, Fekadu Fufa ${ }^{2}$, Abubekir J. Hussen ${ }^{3}$ \\ ${ }^{1}$ Lecturer in Civil Engineering Department, Mettu University, Mettu, Ethiopia \\ ${ }^{2}$ Currently works at Water Supply and Environmental Engineering Chair, Jimma Institute of Technology, Jimma University, Jimma, Ethiopia \\ ${ }^{3}$ Currently works at Civil and Environmental Engineering Department, Highway Engineering Chair, Jimma Institute of Technology, Jimma \\ University, Jimma, Ethiopia
}

\section{Email address:}

assefa.takele.getaneh@gmail.com (A. T. Getaneh), Fekaduff2010@gmail.com (F. Fufa), abukij57@gmail.com (A. J. Hussen)

\section{To cite this article:}

Assefa Takele Getaneh, Fekadu Fufa, Abubekir J. Hussen. Suitability of Gypsum and Crushed Waste Brick Mix for Stabilization of Weak Subgrade Soil. International Journal of Transportation Engineering and Technology. Vol. 6, No. 4, 2020, pp. 111-117.

doi: $10.11648 /$ j.jitet.20200604.11

Received: October 17, 2020; Accepted: October 29, 2020; Published: November 9, 2020

\begin{abstract}
The strength of the road subgrade for, which mostly causes significant damage to structures such as buildings, roads and bridges due to their swell-shrink effect. In the area of expansive soil and scarcity of suitable construction materials, upgrading the locally available materials is one of best alternative ways. Soil stabilization by adding additives is one of the methods of upgrading substandard materials. Therefore this study assessed the suitability of gypsum and crushed waste brick mix for stabilization of expansive soil to use as a road subgrade preparation. Expansive soil sample was collected from Ilubabora zone and was investigated. Accordingly, expansive soil was stabilized with the mix of crushed waste brick and gypsum material proportion of $0 \%, 10 \%, 20 \%, 30 \%, 40 \%$ and $0 \%, 2 \%, 4 \%, 6 \%, 8 \%$ respectively by weight of the total mix and laboratory tests such as Moisture Content, Grain size distribution, Atterberg Limit, Free Swell, Free Swell Index, Free Swell Ratio, Specific Gravity, Compaction, CBR and CBR-Swell are carried out to assess the alteration in its strength characteristics and index properties. The subgrade material quality improved from A-7-5 to A-2-4 at combination $30 \%$ of crushed waste brick and $6 \%$ of gypsum with expansive soil. By the addition of stabilizer material to expansive soil the least plasticity index value obtained was $9.030 \%$ and the CBR increased to $10.686 \%$ from initial $\mathrm{CBR}$ value at the percentage of $30 \%$ brick and $6 \%$ gypsum. The OMC and MDD was increased to $29.200 \%$ and $1.480 \mathrm{~g} / \mathrm{cm}^{3}$ respectively and the free swell, free swell index, free swell ratio was decreased to $18 \%, 16.830 \%, 1.168$ respectively and CBR-Swell decreased to $1.370 \%$, from the initial untreated soil test at percentage of $40 \%$ crushed waste brick and $8 \%$ gypsum mix with expansive soil. Treating expansive soil with the mix of crushed waste brick and gypsum respond and exhibited an improvement on its engineering properties including reduction in plasticity, increased strength and compaction characteristics.
\end{abstract}

Keywords: Crushed Waste Brick, Expansive Soil, Gypsum, Stabilization

\section{Introduction}

Worldwide the availability of natural construction materials within reasonable hauling distance is one of the major factors that have a direct impact on the investment cost of road projects. In areas where natural construction materials are readily available, roads can be constructed on Sound economic basis. However in some regions, natural construction materials are either not available or do not fulfill the quality requirements of road construction materials. Problems associated with these construction materials have been reported in Africa, Australia, Europe, India, and South America, the United States as well as some regions in Canada. In the United States alone, expansive clays have been estimated to produce at least two billion dollars of damage annually. In many areas of the tropics especially Africa and India, tropical expansive soils often known as black cotton soils are the major problematic soils. These soils show very strong swelling and shrinkage characteristics 
under changing moisture conditions [1].

Expansive soil is one of the most abundant soils in Ethiopia and unsuitable subgrade material covering about $40 \%$ of the area of Ethiopia [2]. Which mostly creates problems on built of structure. These problems need wider application of cost effective and environmental friendly technology of improving soil properties to be customized or adopted to the current road construction trend in Ethiopia. The swell-shrink effect of expansive soils causes significant damage to structures such as buildings, roads and bridges. This damage is due to moisture fluctuation caused by seasonal variation. One of the weak sub grade soils that not favorable for road construction is expansive soils. Properties of the weak sub grade soil vary from place to place due to topography, climate and content soils etc. Expansive soils are the soils which swell significantly when they come in contact with water and shrink when dry [3]. Expansive soil exhibit volume change when subjected to moisture variation. Swelling or expansive clays soil is those that contain swelling clay mineral and have high degree of shrink-swell reversibility with change in moisture content [4].

In general way treatment of unsuitable subgrade soils is accomplished by modification, stabilization, or removal and replacement. Modification refers to a short-term subgrade treatment that is intended to provide a stable working platform during construction. Stabilization refers to a subgrade treatment intended to provide structural stability for improved long-term performance. Removal and replacement, as the name indicates, involves removal of the unsuitable subgrade soil and replacement with a select material (usually granular backfill).

From several methods that available to mitigate the effects of swell-shrink nature of expansive soil is to stabilize it with admixtures that prevent it from volume changes or adequately modify the volume change characteristics of expansive soils [3]. Stabilization in a broad sense incorporates the various method employed for modifying the properties of a soil to improve its engineering performance.

Stabilizing agents are selected according to the type of soil and stability problem at hand and the economics of their use. The problem of waste disposal has become a major concern for planners and engineers in developed cities like Mettu.

According to the researchers [5] says demolished waste from the construction can also be used as an admixture to improve the stability of the soil and also DBW has many of its chemical properties similar to cement and as cement can be used for the stabilization of soil so can DBW. Demolished Bricks Waste is inexpensive and readily available so it is a better option for stabilization of soil.

According to, ERA [6] manual proposes: Alignment improvement (avoiding the area of expansive soil), Excavation/soil replacement (replacing expansive soil with good quality material along the road route), Stabilization with stabilizing agent and Minimizing of water content change (implementing measure to prevent water infiltration).

\section{Statement of the Problem}

The fact that expansive soils are major engineering problem makes their study an important aspect due to their tendency to swell in presence of moisture and shrink in moisture absence and the accruing cost involved in terms of economic loss when construction is undertaken without giving consider to the probability of their presence. A difficult problem in civil engineering works exists when the sub-grade is found to be clay soil. Soils having high clay content have the tendency to swell when their moisture content is allowed to increase [7].

Ethiopia is one of the country that have distributed weak subgrade soils. To reduce the impact of weak road subgrade soils, improvement of their engineering properties is required. Stabilizations is commonly used to improve the performance of soils with high plasticity, poor workability, and low strength and stiffness. To achieve effective soil stabilization, special attention needs to be given to proper type and concentration of the stabilizer. Besides, the effectiveness and efficiency of the stabilizer in terms of strength and durability improvement should be stated and specified. The strength and bearing capacity of the soil is impressively enhanced by soil stabilization through controlled compaction, proportioning and the expansion of reasonable admixtures [8].

Therefore, this research was used the mix of gypsum with crushed waste brick which available and cheap as stabilizer to evaluate the index properties, Atterberg limits, compaction and strength of the weak road subgrade soils and their behavior before and after stabilization.

\section{Objective of the Study}

The objective of this study is to evaluate the Suitability of Gypsum and Crushed Waste Brick Mix as stabilizer of weak subgrade soil.

\section{Literature Review}

The researcher states that the moisture content of the subgrade soil is governed by the local climate and the depth of the water table on the road surface [9]. According to ERA, 2002 volume 1 (Flexible pavements and gravel roads) chapter three explains details concerning subgrade materials. According to the manual the strength of the Subgrade soil is assessed by the type of soil, its density and moisture content. According to ERA manual 2002 subgrades are classified from S1 to S6 based on the California bearing ratio (CBR), and are illustrated in table below.

Table 1. CBR Range Subgrade Class [9].

\begin{tabular}{lll}
\hline No. & Class & \%CBR Range \\
\hline 1 & S1 & 2 \\
2 & S2 & $3-4$ \\
3 & S3 & $5-7$ \\
4 & S4 & $8-14$ \\
5 & S5 & $15-29$ \\
6 & S6 & $30+$ \\
\hline
\end{tabular}


According to the soil and materials investigation report, sections of the route with CBR $>3.5 \%$ and swell of about $2 \%$ can be used for Embankment construction which needs to be covered with blanketing material but if the CBR $>15 \%$ good subgrade material it not need covered with blanketing material [10]. From Bowls, 1992 CBR values and the quality of subgrades in pavement design are explained below.

Table 2. CBR range Subgrade quality [10].

\begin{tabular}{lll}
\hline No. & CBR (\%) Range & Subgrade Quality \\
\hline 1 & $0-3$ & Very poor subgrade \\
2 & $3-7$ & Poor to fair subgrade \\
3 & $7-20$ & Fair subgrade \\
4 & $20-50$ & Good subgrade \\
5 & $50+$ & Excellent subgrade \\
\hline
\end{tabular}

The California Bearing Ratio test is conducted for evaluating the suitability of a soil for use as a sub grade, sub base or base course material in highway construction form laboratory conducted specimen. The test measures the shearing resistance of a soil under controlled moisture and density conditions, i.e., usually at optimum moisture content and corresponding degree of maximum dry density relevant to field compaction value [15].

The California bearing ratio (CBR) is to determine the relationship between force and penetration when a cylindrical plunger of a standard cross-sectional area is made to penetrate the soil at a given rate. At certain values of penetration that ratio of the applied force to a standard force expressed as a percentage.

The CBR values are used to determine the thickness of various layers. As it is evident, the required thickness of construction above a material decreases as the CBR value increases.

Addis Ababa City Roads Authority pavement design manual (2004) specifies subgrade materials with CBR values less than $3 \%$ and swelling potential greater than $2 \%$ need to be treated with stabilizing agents or replaced. The manual also recommends subgrade material which has been stabilized should not be assigned a CBR value of more than $15 \%$ for design purposes [16].

\section{Materials and Methods}

\subsection{General Description of the Sampling Area}

The place of sample was located in the Ilubabora Zone of Oromia Region and $600 \mathrm{Km}$ far from Addis Ababa, the capital city of Ethiopia. This location was found between latitude and longitude of $8^{\circ} 17^{\prime} 04^{\prime \prime} \mathrm{N} 35^{\circ} 36^{\prime} 17^{\prime \prime} \mathrm{E}$ and $8^{\circ} 19^{\prime} 39^{\prime \prime} \mathrm{N}$ $35^{\circ} 32^{\prime} 09^{\prime \prime} \mathrm{E}$ and the altitude of the center of the town was $1605 \mathrm{~m}$. Mettu is the capital town of Ilubabora Zone.

\subsection{Study Variables}

There are two type of variables that have been taken into consideration. The dependent variables for this research is the strength of gypsum and crushed waste brick mix stabilized subgrade soil whereas the independent is the physical \&
Engineering properties of untreated and treated weak subgrade Soil and Dosage of Gypsum-Brick waste.

\subsection{Data and Sample Collection Process}

Data collection process included: Field visual inspection, field investigation, after finished the initial visual inspection and categorized the soil conditions of the area and then selected the representative locations for sampling based on the availability of expansive soil. Disturbed soil sample was excavated from test pit up to a maximum depth of $1.5 \mathrm{~m}$ in order to avoid the inclusion of organic matter. The soil sample collected was black cotton soil and selected for laboratory test due to its expansiveness. Finally the results from laboratory test were analyzed with standard specifications.

\subsection{Sample Preparation}

The weak subgrade soil were mixed with the crushed brick and gypsum by percentage of the weight of soil taken for each samples tests starting from 0 to $40 \%$ within $10 \%$ difference and 0 to $8 \%$ within $2 \%$ difference respectively. That means a total of five samples of weak subgrade soil with and without stabilizer were subjected to Atterberg limit, Sieve analysis, free swell, Free Swell Index, Free Swell Ratio, Specific gravity, Compaction, CBR and CBR-Swell tests.

Table 3. Mix Proportion of Materials.

\begin{tabular}{llll}
\hline \multirow{2}{*}{ No. } & Materials & & \\
\cline { 2 - 4 } & $\begin{array}{l}\text { Weak Subgrade } \\
\text { Soil (WSS, \%) }\end{array}$ & $\begin{array}{l}\text { Crushed Waste } \\
\text { Brick (CWB, \%) }\end{array}$ & Gypsum (G, \%) \\
\hline 1 & 100 & 0 & 0 \\
2 & 88 & 10 & 2 \\
3 & 76 & 20 & 4 \\
4 & 64 & 30 & 6 \\
5 & 52 & 40 & 8 \\
\hline
\end{tabular}

\section{Result and Discussion}

\subsection{Engineering Properties of Natural Soil}

The results of the tests conducted for identification and/or determination of properties of the natural soil before applying gypsum and crushed waste brick are discussed as follow.

\subsubsection{Grain Size Analysis}

The result from the test is used to determine the particle size distribution with applicable specification requirement and it also helps to determine the soil class together with the Atterberg limits. As shown in Figure 1 on the particle size distribution curve almost $85.650 \%$ of the soil is passing through No. 200 sieve size and $60.920 \%$ was silty soil and $57.160 \%$ was clay soil.

\subsubsection{Atterberg Limit Test}

The Liquid Limit and Plastic Limits of soil indicate the water contents a certain changes in the physical behavior of soil that was being observed. Depending on the result of Plastic index the natural soil is highly plastic clay [11]. 


\subsubsection{Compaction Test}

Compaction test has been conducted for the natural soil under consideration to determine the maximum dry density and optimum moisture content of the soil. From MoistureDensity Content Relationship graph or compaction curve the optimum moisture content is $25.400 \%$ and the maximum dry density becomes $1.412 \mathrm{~g} / \mathrm{cm}^{3}$.

\subsubsection{California Bearing Ratio (CBR) Test}

Table 4. Geotechnical properties of the natural soil.

\begin{tabular}{ll}
\hline Property of Soil & Observed Value \\
\hline Natural Moisture Content (NMC), \% & 30.560 \\
Percentage Passing No. 200 Sieve, \% & 85.650 \\
Silty,\% (0.05mm-0.002mm) & 60.920 \\
Clay, \% (<0.002mm) & 57.160 \\
Liquid Limit (LL), \% & 76.500 \\
Plastic Limit (PL), \% & 40.000 \\
Plastic Index (PI), \% & 36.500 \\
Group Index (GI) & 38.000 \\
AASHTO soil classification & $\mathrm{A}-7-5$ \\
USCS group symbol & $\mathrm{MH}, \mathrm{CH}$ and $\mathrm{OH}$ \\
Specific Gravity (Gs) & 2.650 \\
Free Swell (FS), \% & 82.000 \\
Free Swell Index (FSI), \% & 60.920 \\
Free Swell Ratio (FSR) & 1.609 \\
Maximum Dry Density (MDD), g/cm3 & 1.412 \\
Optimum Moisture Content (OMC), \% & 25.400 \\
Soaked CBR value, \% & 1.456 \\
CBR-Swell, \% & 6.560 \\
Colour & Black \\
\hline
\end{tabular}

From Table 4 CBR value test result is less than $3 \%$, this show that the material is not used for construction of Subgrade layer or it need treatment [16].

Hence, the soil was found to be highly plastic expansive clay with low bearing capacity when it is soaked and high swelling potential and fell below the standard recommendations for most geotechnical construction works especially highway construction.

\subsubsection{Properties of Crushed Brick and Gypsum}

Bricks are produced from clay with high temperature kiln firing or from ordinary Portland cement (OPC) concrete [13]. Gypsum is a soft white mineral consisting of hydrated calcium sulfate. The chemical formula is calcium sulfate dehydrate $\left(\mathrm{CaSO}_{4} \cdot 2\left(\mathrm{H}_{2} \mathrm{O}\right)\right)$. By weight it is $79 \%$ calcium sulphate and $21 \%$ water. Gypsum has $23 \%$ calcium and $18 \%$ sulphur [14].

Table 5. Properties of Crushed Brick and Gypsum.

\begin{tabular}{lll}
\hline Properties & Brick & Gypsum \\
\hline Specific gravity at 20oc, Gs & 2.010 & 2.380 \\
Liquid Limit, LL (\%) & 40.250 & N. L. \\
Plastic Limit, PL (\%) & N. P. & N. P. \\
Plastic Index, PI (\%) & - & - \\
Free swell, \% & 10.000 & 1.000 \\
\hline
\end{tabular}

Depending on laboratory test Table 5 Specific gravity test result of gypsum was high relative to brick, but less relative to soil.

\subsection{Effect of the Mix of Gypsum and Crushed Waste Brick on Expansive Soil Engineering Properties}

\subsubsection{The Effect of Gypsum and Crushed Waste Brick Mix on Atterberg Limit}

Table 6. Laboratory test results of Atterberg Limit.

\begin{tabular}{lllll}
\hline Natural Soils and Percent's of Stabilizer & LL (\%) & PL (\%) & PI (\%) & The reduction of PI (\%) \\
\hline WSS $+0 \%$ CWB $+0 \%$ G & 76.500 & 40.000 & 36.500 & - \\
WSS $+10 \%$ CWB $+2 \%$ G & 74.400 & 38.800 & 35.620 & 2.410 \\
WSS + $20 \%$ CWB $+4 \%$ G & 60.220 & 34.480 & 25.740 & 27.740 \\
WSS $+30 \%$ CWB $+6 \%$ G & 40.000 & 30.970 & 9.030 & 64.920 \\
WSS $+40 \%$ CWB $+8 \%$ G & 39.800 & N. P. & - & - \\
\hline
\end{tabular}

The highest reduction in plastic index occur when it was stabilized by the combination of $30 \%$ brick with $6 \%$ gypsum ratio and the minimum reduction occur when it was stabilized by the combination of $10 \%$ brick with $2 \%$ gypsum ratio.

\subsubsection{The Effect of Gypsum and Crushed Waste Brick Mix on Soil Classification}

Table 7. Soil Classification.

\begin{tabular}{lllll}
\hline \multirow{2}{*}{ Sample } & Atterberg Limit & & & Soil Classification \\
\cline { 2 - 5 } & LL & PL & PI & AASHTO \\
\hline Expansive soil & 76.500 & 40.000 & 36.500 & A-7-5 \\
WSS+10\%CWB+2\%G & 74.400 & 38.800 & 35.620 & A-7-5 \\
WSS+20\%CWB+4\%G & 60.220 & 34.480 & 25.740 & A-7-5 \\
WSS+30\%CWB+6\%G & 40.000 & 30.970 & 9.030 & A-2-4 \\
WSS+40\%CWB+8\%G & 39.800 & - & - & - \\
\hline
\end{tabular}

\subsubsection{Effect of Gypsum and Crushed Waste Brick Mix on Swelling Characteristics \\ i. Free Swell}

The effect of gypsum and crushed waste brick mix on the free swell of the expansive soil is shown in Figure 1.

According to results shown in figure 1, increasing the mix proportion of Gypsum and Crushed Waste Brick reduces the free swell of expansive soil to $18 \%$ from $82 \%$ when $40 \%$ crushed waste brick and $8 \%$ gypsum was added. This is due 
to crushed waste Brick a strong inter particle bond develops with gypsum and soil, this cementing bond offers great resistance to swelling and also does not allow the water to escape from soil to induce shrinkage. The highest reduction in free swell is attained when the expansive soil is treated with $30 \%$ of crushed waste brick and $6 \%$ of gypsum mix which is $58.850 \%$ reduction compared to untreated expansive soil. Generally the result showed the combination of crushed waste brick and gypsum were effective to reduce the swelling potential of expansive soils.

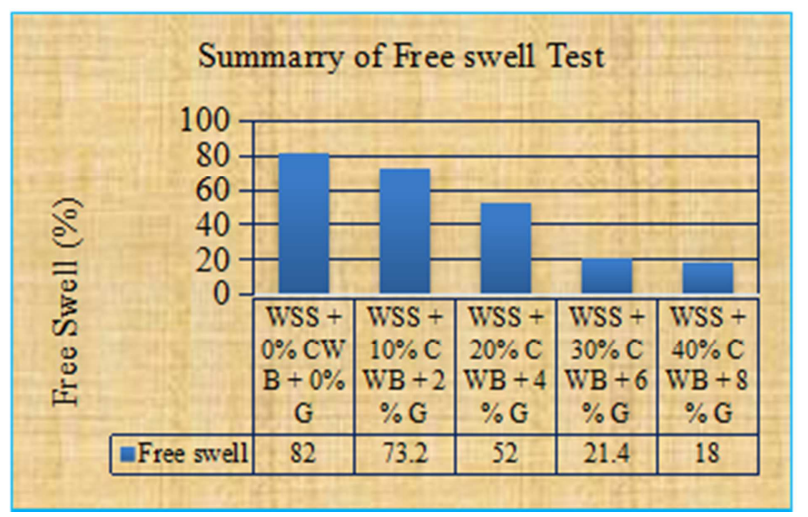

Figure 1. Changes in free swell with varying percentage of gypsum and crushed waste brick.

\section{ii. Free Swell Index}

The effect of gypsum and crushed waste brick mix on the free swell index of the expansive soil is shown in Figure 2. According to results shown in figure, as increasing the percentage of Gypsum and Crushed Waste Brick mix, reduces the free swell index of expansive soil from $60.920 \%$ to $16.832 \%$ when $40 \%$ crushed waste brick and $8 \%$ gypsum was added. The highest reduction in free swell index is $56.150 \%$ attained when the expansive soil is stabilized with $30 \%$ of crushed waste brick and $6 \%$ of gypsum mix when compared to unstabilized expansive soil. The swelling potential reduced form very high to medium as the content of Gypsum and Crushed Waste Brick became increased. The Degree of Expansion of treated sample became low due to increasing of Gypsum and Crushed Waste Brick [12].

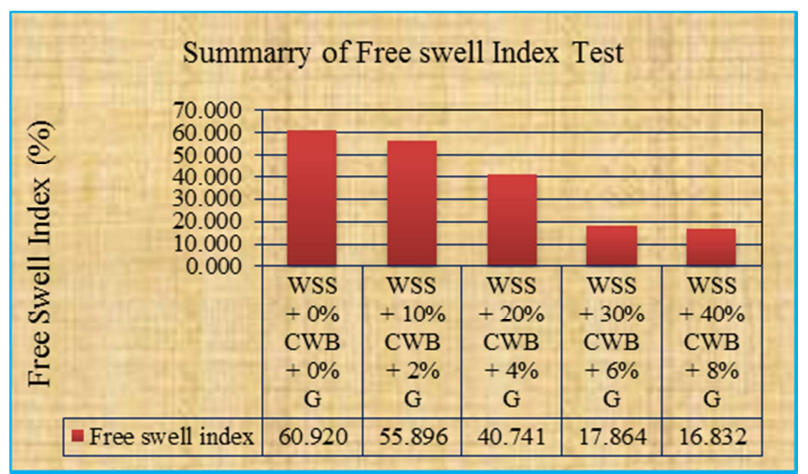

Figure 2. Changes in free swell index with varying percentage of gypsum and crushed waste brick.

\section{iii. Free Swell Ratio}

As it is shown in Figure 3. When the mix of gypsum and crushed waste brick added to the expansive soil the free swell ratio decreased. As the content of gypsum and crushed waste brick mix increased from $0 \%$ to $8 \%$ gypsum $+40 \%$ brick, the free swell ratio decreased from 1.609 to 1.168. The highest reduction in free swell ratio is $16.250 \%$ attained when the expansive soil is stabilized with $30 \%$ of crushed waste brick and $6 \%$ of gypsum mix when compared to unstabilized expansive soil. The Soil Expansivity of treated sample became low due to increasing the percentage of Gypsum and Crushed Waste Brick to expansive soil [12].



Figure 3. Changes in free swell ratio with varying percentage of gypsum and crushed waste brick.

\subsubsection{The Effect of Gypsum and Crushed Waste Brick Mix on Compaction}

From Figure 4 the results showed that as stabilization proportion has increased, the optimum moisture content and maximum dry density increased. The Expansive soil laboratory test $\mathrm{OMC}$ increased from $25.400 \%$ at $0 \%$ brick and gypsum to $29.200 \%$ at $40 \%$ brick and $8 \%$ gypsum. It is observed that maximum dry density of Expansive soil was increased from 1.412 to $1.480 \mathrm{~g} / \mathrm{cm}^{3}$ up to addition of $40 \%$ crushed brick and $8 \%$ gypsum expansive soil. This is because of the frictional resistance from crushed waste brick dust in addition to the cohesion from expansive soil and gypsum gives the binding property to the soil.

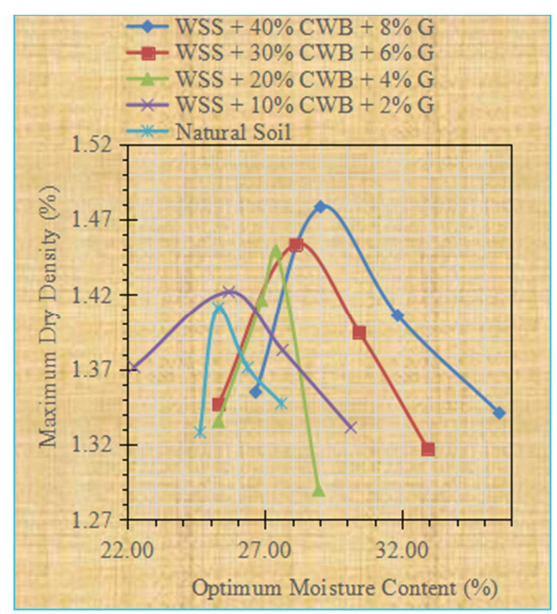

Figure 4. Density-Moisture Content Relationship 


\subsubsection{Effect of the Mix of Gypsum and Crushed Waste Brick on CBR and CBR-Swell \\ i. $C B R$ at $95 \%$ of Compaction}

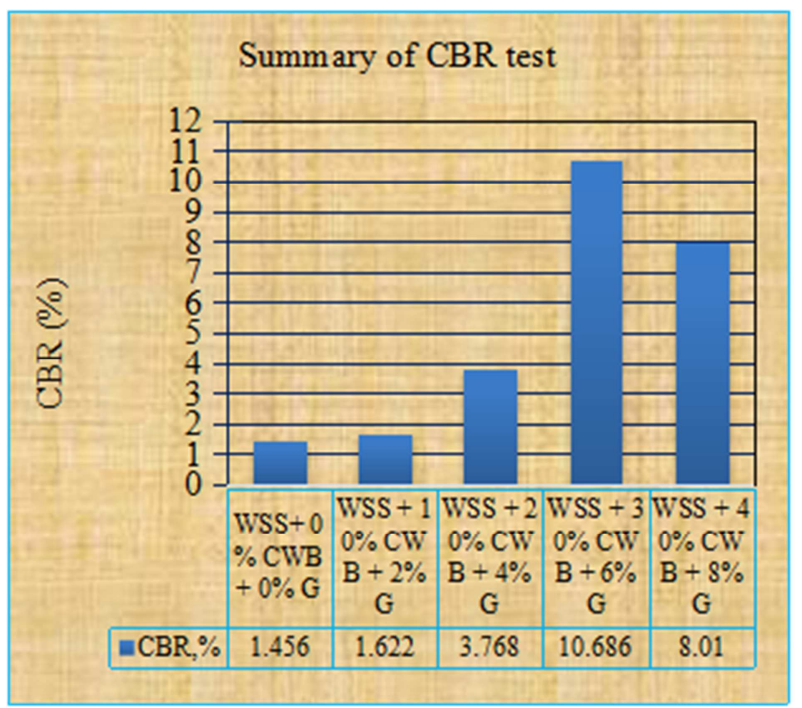

Figure 5. The CBR value at $95 \%$ of compaction.

The CBR value at $95 \%$ of compaction determined from the relation of corrected CBR and percent of compaction graph. The effect of gypsum and crushed waste brick mix on the CBR of Expansive soil was presented in the Figure 5. The soaked CBR value at $95 \%$ of compaction of the unstabilized and stabilized Expansive soil sample improved from 1.456\% to $10.686 \%$ at combination of $30 \%$ of crushed waste brick and $6 \%$ of gypsum. The treated expansive soil is improved to S4 subgrade class. This shows that the mix of gypsum and crushed waste bricks stabilizer agent can effectively stabilize an expansive soil for a road construction.

According to the researcher justified that $\mathrm{CBR}>3.5 \%$ and swell of about $2 \%$ can be used for Embankment construction which needs to be covered with blanketing material but if the CBR $>15 \%$ good subgrade material it not need covered with blanketing material [10]. Therefore, the improved expansive soil using the mix of Gypsum and crushed waste Bricks was need to be covered with blanketing material when preparing subgrade layer.

Generally, the CBR value started to decrease when it reached to the combination expansive soil with the percentage of $40 \%$ of crushed waste brick and $8 \%$ of gypsum mix. The percentages above the mix of $20 \%$ of crushed waste brick and $4 \%$ of gypsum were satisfied the quality and the strength the expansive soils. Thus we can take gypsum and crushed waste brick as a weak subgrade soils stabilizer for road subgrades, but need covered with blanketing material.

ii. CBR-Swell \%

The effect of gypsum-brick on the CBR-Swell of Expansive soil is presented in the Figure 6.

From the Figure 6, the percent swell of the stabilized weak expansive soils samples are decreased linearly as the percentage of stabilizer getting increased and vice versa. The CBR-Swells are decreased from $6.560 \%$ to $1.370 \%$ as the percent of stabilizer agent increased. This means the swell and the amount of stabilizer have inversely proportional relation. When the value of the percent CBR-Swell decreased the properties of the soil is getting improved.

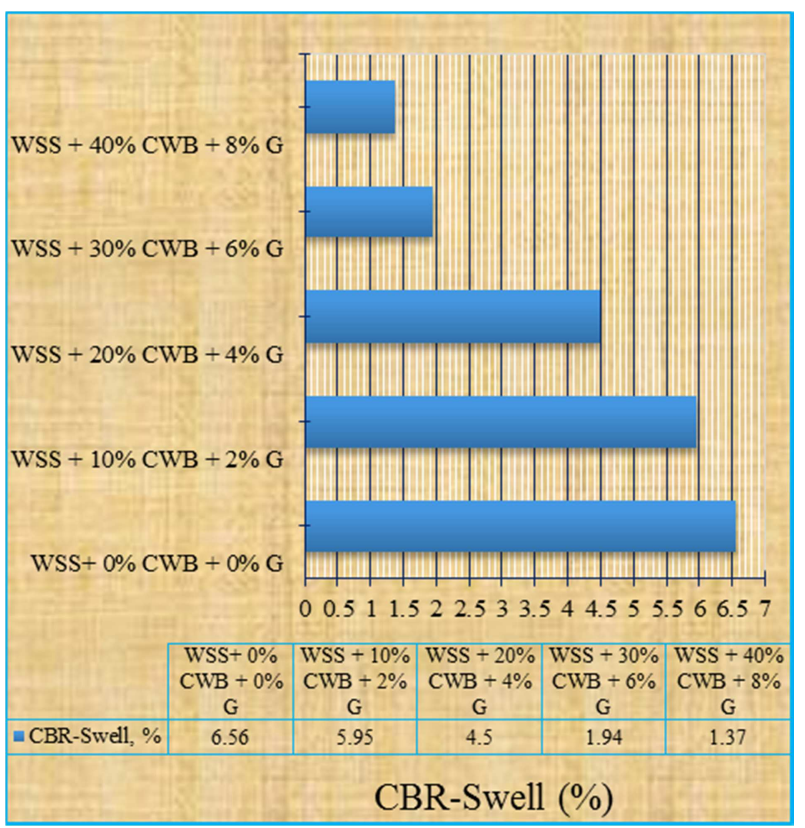

Figure 6. Graphical representation of gypsum-crushed waste brick \% Vs CBR-Swell.

\section{Conclusion}

From the laboratory output Expansive soils are characterized by volume change due to variation in moisture content and also these soils swell when they get moisture and shrink when they are dry. Therefore, these problematic soils when encountered as sub grade should be avoided or treated properly.

The objective of this study is to quantify the improvements achieved on the engineering properties of expansive soils due to the mix of gypsum and crushed waste brick stabilization. The laboratory tests conducted for this study were moisture content, specific gravity, grain size analysis, Atterberg limits, free swell test, free swell index, compaction, CBR and CBR swell tests. The test procedures were based on AASHTO and ASTM laboratory test standards. The stabilization was done using 10,20, 30 and $40 \%$ of crushed waste brick and 2, 4, 6 and $8 \%$ of gypsum by weight. From the study the following findings are deduced:

The properties of natural sub grade soils was expansive clay soil, Based on the AASHTO (American Association of State Highway Transportation Official) soil classification system, the original soil samples was A-7-5 and the group index was 38, Based on the AASHTO soil classification was grouped under poor subgrade soil, The sub grade soils considered for this study have a very low load bearing capacity and high swelling potential which makes the soils unsuitable for sub grade without improvement, The specific gravity of original expansive soil was 2.650. The specific gravity of the gypsum was 2.380 and the specific gravity of 
crushed brick was 2.010, The liquid limit and the plastic limit decreased from $76.500 \%$ to $39.800 \%$ and $40.000 \%$ to non-plastic respectively as the amount of gypsum and crushed waste brick mix was increased, The plastic index is decreased from $36.500 \%$ to $9.030 \%$ and The soil classification improved to A-2-4 at stabilization of soil with $30 \%$ crushed waste brick and $6 \%$ gypsum based on AASHTO soil classification system, The optimum moisture content increased with increment of gypsum and crushed waste brick content. The optimum moisture content of weak subgrade soil changed from $25.400 \%$ to $29.200 \%$, the engineering properties of the expansive soils is improved due to stabilized by gypsum and crushed waste brick stabilizer. The free swell, free swell index, free swell ratio, CBR-Swell were decreased from $82.000 \%$ to $18.000 \%$, $60.920 \%$ to $16.830 \%, 1.609$ to $1.168,6.560 \%$ to $1.370 \%$ respectively and MDD increased from $1.412 \mathrm{~g} / \mathrm{cm}^{3}$ to $1.480 \mathrm{~g} / \mathrm{cm}^{3}$ as the increment of gypsum and crushed waste brick to $40 \%$ of crushed waste brick and $8 \%$ of gypsum mix The CBR value increases from $1.456 \%$ to $10.686 \%$ as the content of gypsum and crushed waste brick increases from $0 \%$ to $6 \% \mathrm{G}+30 \% \mathrm{CWB}$ then decreased to $8.010 \%$ as increased the stabilizer to $8 \% \mathrm{G}+40 \% \mathrm{CWB}$.

Generally the mix of crushed waste brick with gypsum can effectively utilized with weak subgrade soil in improving the soil CBR values and MDD. The use of Crushed Brick resulted in utilization of demolition wastes and found to be economical for local area. This will results in the utilization of rejected weak soil in construction. From the results, it is concluded that impact of Crushed Brick and Gypsum is positive.

\section{References}

[1] Bhavanna Rao. Adverse effects of using natural gravel in sub base, base and Water Bound Macadam. 2005.

[2] Ehitabezahu Negussie, Abebe Dinku. Investigation on the Effects of Combining Lime and Sodium Silicate for Expansive Subgrade Stabilization. Adis Abeba. 2014.
[3] James, Lakshmi, Pandian. Strength and Index Properties of Phosphogypsum Stabilized Expansive Soil. International Journal of Applied Environmental Sciences. 2014.

[4] Iytton. Concept of pavement performance prediction and modeling. Texas,second pavement manegment conference. 1987.

[5] Kumar, Agrawal, Dobriyal. Stabilization of Soil using Demolished Brick Waste. Innovations and Advances in Civil EngineeringTowards Green and Sustainable Systems. 2018.

[6] ERA. Site investigation manual: Ethiopian Road Authority, Addis Ababa. 2013.

[7] Murthy, et al. Chemical Stabilization of Sub-Grade Soil with Gypsum and Nacl. International Journal of Advances in Engineering \& Technology. 2016.

[8] Tiwari, Hringi, Chaudhary. Review on stabilization of black cotton soil by brick dust \& lime. International Journal of Advance Research in Science and Engineering. 2018, 7.

[9] Ethiopian Roads Authority. "Pavement Design Manual,". Addis Ababa. 2002.

[10] Bowles, J. "Engineering properties of soil and their measurements," McGraw-Hill Boston, 1992.

[11] Whitlow, R. Basic Soil Mechanics,"3rd ed. Edinburgh Gate. 1995.

[12] Amer, Ali Al-Rawas, Matheus, F A. Expansive Soils recent advances in characterization and treatment: Taylor \& Francis Group, London, UK. 2006.

[13] Zhang. Production of bricks from waste materials. Construction and Building Materials. 2013.

[14] Murthy, N, et al. Chemical stabilization of sub-grade soil with Gypsum and $\mathrm{NaCl}$. India: International Journal of Advances in Engineering \& Technology. 2016.

[15] Dr. Arora, R K. Soil Mechanics and Foundation Engineering. [book auth.] Arora. Soil Mechanics and Foundation Engineering. A. k. Jain. 2003.

[16] Bowles, G E. Engineering properties of Soil and their Measurement. McGraw Hill Book Company. U.S. America. 1978. 